\title{
Practices, Challenges and Opportunities of Using Afan Oromo as a Medium of Instruction in Upper Primary Schools of Berbere Woreda, Bale Zone, Oromia, Ethiopia
}

\author{
Bezabih Wondimu ${ }^{1, *}$, Tesfaye Guta ${ }^{2}$ \\ ${ }^{1}$ Department of Educational Planning and Management, College of Education and Behavioral Studies, Madda Walabu University, Bale Robe, \\ Ethiopia \\ ${ }^{2}$ Barbere Woreeda, Oromia, Ethiopia
}

Email address:

bezabih19@yahoo.com (B. Wondimu)

${ }^{*}$ Corresponding author

\section{To cite this article:}

Bezabih Wondimu, Tesfaye Guta. Practices, Challenges and Opportunities of Using Afan Oromo as a Medium of Instruction in Upper Primary Schools of Berbere Woreda, Bale Zone, Oromia, Ethiopia. International and Public Affairs. Vol. 4, No. 2, 2020 , pp. 35-43. doi: $10.11648 /$ j.ipa.20200402.13

Received: April 15, 2020; Accepted: May 5, 2020; Published: September 10, 2020

\begin{abstract}
The main purpose of the study was to investigate practices, challenges and opportunities of using Afan Oromo as a medium of instruction in upper primary schools of Berbere Woreda, Bale Zone, Oromia. To attain the purpose of the study, mixed research design, that put on both quantitative and qualitative research methods were employed and more specifically, concurrent triangulation mixed research design was employed. 45 teachers and 395 sample students were selected by using simple random sampling techniques respectively. Whereas, nine CRC supervisors and nine principals were selected by purposive sampling techniques. Questionnaires and interviews were used as data collection tools. Analysis of the data was done using descriptive and inferential statistics like frequency distribution (fd), percentage (\%) mean (m) and t-test. The qualitative data was analyzed by narration and personal interpretation of the researcher. The finding of the study showed that; although there are the practices of using Afan Oromo as a medium of instruction, these practices are challenged by the absence of adequate reference materials and existence of negative perception of parents, students and local communities. The availability of Ethiopian Education and training policy and language policy has enormous opportunity for the use of mother tongues such as Afan Oromo as medium of instruction. So, to use Afan Oromo as medium of instruction in the upper primary school, it's better to fulfill necessary supplies and exercise every opportunity that supports this practice. Finally, based on the findings of the study, the researcher recommended that strong collaboration among stakeholders needs to be undertaken to ensure the real practice of using Afan Oromo as medium of instruction in upper primary schools of Berbere Woreda, Bale Zone, Oromia, South East Ethiopia.
\end{abstract}

Keywords: Practices, Challenges, Opportunities, Afan Oromo, Mother Tongue

\section{Introduction}

\subsection{Background of the Study}

One way of ensuring quality education is using an appropriate medium of instruction that is familiar to both teachers and students. Studies suggest that children who learn in their first or immediate language are more competent than those children who learn in an unfamiliar language. If children begin learning in a language they know and understand they can connect their learning to their experiences and knowledge that they have gained from their parents, cultures, oral narratives and local community as explicated. A language of instruction used in the classroom plays a great role in delivering concepts, knowledge or contents of the subject to be learnt. [1] States that:

The root of the argument is that if a medium of instruction is a language of a child, he /she easily understand the contents of learning instructions. Evidences indicated that the child could associate what he/she has learned in the 
classroom with the previous knowledge and experiences that he/she accumulated from their local environment.

This clearly indicates that the use of a language that is familiar to both teachers and students plays a profound role in facilitating their learning and teaching. The use of a familiar language also enhances the use of active learning and teaching approaches in the classrooms. The endorsement of the 1994 constitution of Ethiopia supported and adopted the multilingual policy.

The Constitution produced in the article 39 and subtitle 2, which reads "Every Nation, Nationality and People of Ethiopia has the right to speak, to write and to develop its own language; to express, to develop and to promote its culture; and to keep its history" [2]. The constitution guarantees everyone in the country to use and develop his or her language, cultures, wisdom and history.

The Education and Training Policy of Ethiopia 1994 recognized the use of children's home languages in primary school education. The document depicted, "Cognizant of the pedagogical advantage of the child in learning in mother tongue and the rights of the nationalities to promote the use of their languages, primary education were given in nationality languages" [3]. This policy created a tremendous appreciation among the previously marginalized linguistic groups. However, according to [4] some elites that support the unitary government system and the ideology of Emperor Regime and groups that had influential power in the country continued to oppose and criticize the use of many languages in primary school education in Ethiopia [4].

In line with this, [2] the new multilingual policy were seen as a national disintegration and divisive ideology, which could lead to ethnic conflict and fragmentation of the country. Thus, linguistic competition created between the groups those who want to celebrate a linguistic revitalization on the one hand and those groups who want to reject the celebration of linguistic revival on the other hand in and around the schools. However, the researcher denies the above arguments that are against the right of the learners and their ethnic group. Because, those well-established myths and attitudes hamper the use of mother tongue such as Afan Oromo as medium of instruction.

\subsection{Statements of the Problem}

Mother tongue instruction facilitates the integration of the schools, remote rural schools, the surroundings often the illiterate communities which contribute to teaching the indigenous knowledge, production and cultural skills. Moreover, it improves the child's communication and interactions in the classroom which leads to a more successful learning opportunity and when pupils acquire the basic skills (reading, writing and literacy) it facilitated the acquisition of the second language and other school subjects [5].

In supporting this viable idea, [6], suggested that politically it is noted that governments reproduce their own classes through the medium of instruction. Economically, the need to develop multilingualism requires resources in terms of teacher training, developing grammars and orthographies, producing and translating textbooks and supplementary materials. The cost issue is one of the arguments used against development of mother tongue education. The Ethiopian Ministry of Education implemented the use of mother tongue in education for pedagogical advantages and for the rights of nationalities to self-expression that enshrined in the Constitution of Ethiopia [7]. According to the author, the Ministry of Education adopted mother-tongue education for both pedagogical and ideological justification for the promotion of local language use in education in primary schools.

In line with these idea, [1] conducted research on challenges of mother-tongue education in primary schools; the case of Afan Oromo in the Eastern Hararge Zone. The study conducted by (4) in East Hararge shows that the dominance of English as a medium of instruction and an international language in Ethiopian education systems have exerted its impacts on the development of indigenous local languages in general and Afan Oromo in particular, Besides, people's language preferences as a medium of instruction, most parents wanted the use of their language in education, but the use of English as a medium of instruction in higher education negatively affected their perceptions, educational materials like additional reading material, teachers' guides and syllabi were acute shortages in schools. These constraints also opened the door to discourage the use of mother tongue in education.

The previous study investigated only on challenges of using Afan Oromo. However, to the best knowledge of the researcher, no research has been conducted with regards to the practices, challenges and opportunities of the use of mother tongue as a medium of instruction in Bale Zone. Thus, to fill these gaps the following basic research questions were riseed and answered in the course of the study.

1. What are practices of using Afan Oromo as a medium of instruction in upper primary schools of Berebere woreda, Bale Zone, Oromia?

2. What are the opportunities of using Afan Oromo as a medium of instruction in upper primary school of Berebere woreda, Bale Zone, Oromia?

3. What are the challenges that hinder learning and teaching through Afan Oromo as a medium of instruction in upper primary schools of Berbere woreda, Bale Zone?

\subsection{Research Paradigm, Methods and Design Used for the Used}

Among different paradigms used in the research, pragmatism was selected as an appropriate paradigm to investigate the problem under the study. This is because pragmatism as a paradigm helps the researcher to use both positivism and the constructivism in a single study [8]. In line this, mixed research method (both qualitative and quantitative research methods) were employed to undertake the study. More specifically, cconcurrent mixed research design was used for analysis. 


\subsection{Population, Sample and Sampling Techniques of the Study}

45 upper primary schools found in Bale zone of Berbere woreda can be chosen as population of the study. To generalize the findings to the population of the study, sample must be representative of the population in terms of number and representativeness. CRC of primary schools are the strata under category to decide the number sample taken from each school. So, all the nine (13) CRC supervisors were taken as respondent using purposive sampling. Besides, from all nine CRC, total of 395 students were selected using the kind of probability sampling known as stratified sampling. In addition, nine (13) principals were selected using purposive sampling. There are also 45 Afan Oromo (mother tongue) teachers were selected one teacher; that act as department head from each school that were respondent of the study using simple random sampling technique. According to [9] deciding the margin of error, (as much as possible the margin of error should not be higher than 5\%. Probably $3 \%$ is an ideal one).

Generally by using both probability and non-probability sampling techniques, a total of 467 people were used as respondents; in which $9 \mathrm{CRC}$ supervisors, 395 students, 9 principals, 9 PTA heads and 45 Afan Oromo teachers were used.

\subsection{Instruments of Data Collection}

The instruments of data collection utilized in this research were questionnaire, interview and document analysis.

\subsection{Method of Data Analysis}

Both quantitative and qualitative data analysis techniques were used. Quantitative data were collected and analyzed quantitative by the use of both descriptive statistics (frequency distribution, percentage) and t- test of inferential statistics). Qualitative data were analyzed by means of narration, direct quotation and paraphrasing of the views of the respondents.

\section{Data Presentation, Analysis and Interpretation}

\subsection{Practices of Using Afan Oromo as a Medium of Instruction}

This section of the analysis deals with the real practice taken with respect to the use of Afan Oromo as medium of instruction.

Table 1. Classroom Performance of teachers in using Afan Oromo as mother tongue.

\begin{tabular}{|c|c|c|c|c|c|c|c|c|c|c|c|}
\hline \multirow{2}{*}{ S. № } & \multirow{2}{*}{ Items } & \multicolumn{2}{|c|}{ Strongly Disagree } & \multicolumn{2}{|c|}{ Disagree } & \multicolumn{2}{|c|}{ Undecided } & \multicolumn{2}{|c|}{ Agree } & \multicolumn{2}{|c|}{ Strongly agree } \\
\hline & & f & $\%$ & $\mathbf{F}$ & $\%$ & f & $\%$ & f & $\%$ & f & $\%$ \\
\hline 1 & $\begin{array}{l}\text { Using authentic examples from students' cultures } \\
\text { and experiences. }\end{array}$ & 3 & 6.7 & 8 & 17.8 & 7 & 15.6 & 15 & 33.3 & 12 & 26.7 \\
\hline 2 & $\begin{array}{l}\text { Tutorial section that is given for students that have } \\
\text { difficulty of Qubee based writing style }\end{array}$ & 10 & 22.2 & 9 & 20.0 & 3 & 6.7 & 13 & 28.9 & 10 & 22.2 \\
\hline 3 & $\begin{array}{l}\text { Students' language skills and classroom } \\
\text { interaction was assessed by Afan Oromo teachers }\end{array}$ & 6 & 13.3 & 7 & 15.6 & 5 & 11.1 & 15 & 33.3 & 12 & 26.7 \\
\hline
\end{tabular}

Concerning practices of teachers in using Afan Oromo as a medium of instruction in using authentic examples from students' cultures and experiences item 1 in Table 1 , of the teacher respondents respectively responded strongly disagree $3(6.7 \%)$ and disagree $8(17.8 \%)$. While $27(60 \%)$ of the teacher respondents respectively responded agree 15 (33.3\%) and $12(26.7 \%)$ of the teacher respondents strongly agree with the statement that of teachers in using Afan Oromo as a medium of instruction in using authentic examples from students' cultures and experiences. Only 7 (15.6\%) of teacher respondents expressed their feelings as undecided. Thus it can be concluded that teacher using authentic examples from students' cultures and experiences.

In item 2 Table $1,19(42.2 \%)$ of the teacher respondents respectively responded strongly disagree $10(22.2 \%)$ and disagree $9(20.0 \%)$. While more than half or $23(51.1 \%)$ of the teacher respondents respectively responded agree $13(28.9 \%)$ and $10(22.2 \%)$ of the teacher respondents strongly agree with the statement that tutorial section that is given for students that have difficulty of 'Qubee' based writing style. Only $3(6.7 \%)$ of teacher respondents expressed their feelings as undecided. Thus it can be concluded that tutorial section given for students' on the difficulty of Qubee based writing style.

In this regard the qualitative data gathered from CRC supervisors clearly shows that there was promotion of students writing and acting on local culture; especially Afan Oromo clubs that foster cultural folktales and tutorial of Qubee based writing system.

In item 3 Table 1, 13 (28.9\%) of the teacher respondents respectively responded strongly disagree 6 (13.3\%) and disagree $7(15.6 \%)$. While $27(60.0 \%)$ of the teacher respondents respectively responded agree 15 (33.3\%) and 12 $(26.7 \%)$ of the teacher respondents strongly agree with the statement that students' language skills and classroom interaction was assessed by Afan Oromo teachers. Only 5 (11.1\%) of teacher respondents expressed their feelings as undecided. This shows that there was the practice of assessing students towards the basic language skills and classroom interaction.

In item 4 Table 2, $23(51.1 \%)$ of the teacher respondents respectively responded strongly disagree $12(26.7 \%)$ and 
disagree $11(24.4 \%)$. While $19(42.2 \%)$ of the teacher respondents respectively responded agree $8(17.8 \%)$ and $11(24.4 \%)$ of the teacher respondents strongly agree with that there is no frequent Mother tongue (MT) Teachers who uses efficient and innovative methods of teaching. Thus it can be concluded that MT Teachers did not use efficient and innovative methods of teaching.

Through interview, the respondents responded that almost similar with the aforementioned responses. For instance, one of the respondents, CRC1, expressed his views as use of Afan Oromo as a medium of instruction in primary school is crucial to enhance quality of education and facilitates students' learning and academic achievement.

As suggested by [10] shows that teachers need continuous training and awareness creation from time to-time regarding effective methods of teaching and how they can use active learning methods in the classrooms. He also noted that some teachers who taught in the lower grades had a serious problem in teaching English as their teaching methods were unattractive.

\subsection{Opportunities of Using Afan Oromo as Mother Tongue}

Support given to the enhancement of education through Afan Oromo

This section assesses teachers' views regarding support given to the enhancement of learning and teaching through Afan Oromo in primary schools. It focuses on the support given to schools and parents by various stakeholders to raise parents' awareness about the use of Afan Oromo in education in the primary schools.

Table 2. Opportunities of using Afan Oromo as mother tongue.

\begin{tabular}{|c|c|c|c|c|c|c|c|c|c|c|c|}
\hline \multirow{3}{*}{$\begin{array}{l}\text { S. } \\
\text { No }\end{array}$} & \multirow{3}{*}{ Items } & \multicolumn{10}{|c|}{ Respondent Teachers $(\mathrm{N}=45)$} \\
\hline & & \multicolumn{2}{|c|}{ Strongly Disagree } & \multicolumn{2}{|c|}{ Disagree } & \multicolumn{2}{|c|}{ Undecided } & \multicolumn{2}{|c|}{ Agree } & \multicolumn{2}{|c|}{ Strongly agree } \\
\hline & & $\mathbf{F}$ & $\%$ & $\mathbf{F}$ & $\%$ & $\mathbf{F}$ & $\%$ & f & $\%$ & f & $\%$ \\
\hline 1 & $\begin{array}{l}\text { Support was given from school and parents to } \\
\text { encourage students learning through MT }\end{array}$ & 9 & 20.0 & 7 & 15.6 & 8 & 17.8 & 11 & 24.4 & 10 & 22.2 \\
\hline 2 & $\begin{array}{l}\text { Ethnic backgrounds of students is fitting with language } \\
\text { preferences of students as medium of instruction }\end{array}$ & 3 & 6.7 & 4 & 8.9 & 2 & 4.4 & 20 & 44.4 & 16 & 35.6 \\
\hline 3 & $\begin{array}{l}\text { The social backgrounds of students go along with } \\
\text { medium of instruction }\end{array}$ & 2 & 4.4 & 7 & 15.6 & 4 & 8.9 & 15 & 33.3 & 17 & 37.8 \\
\hline 4 & $\begin{array}{l}\text { Learning upper primary education through Afan Oromo } \\
\text { increases confidence of students }\end{array}$ & 3 & 6.7 & 9 & 20.0 & 8 & 17.8 & 13 & 28.9 & 12 & 26.7 \\
\hline
\end{tabular}

Table 2. Continue.

\begin{tabular}{|c|c|c|c|c|c|c|c|c|c|c|c|c|}
\hline \multirow{3}{*}{$\begin{array}{l}\text { S. } \\
\text { No }\end{array}$} & \multirow{3}{*}{ Items } & \multicolumn{11}{|c|}{ Respondent students $(\mathrm{N}=395)$} \\
\hline & & \multicolumn{2}{|c|}{ Strongly Disagree } & \multicolumn{2}{|c|}{ Disagree } & \multicolumn{2}{|c|}{ Undecided } & \multicolumn{2}{|c|}{ Agree } & \multicolumn{2}{|c|}{ Strongly agree } & \multirow{2}{*}{ t- value } \\
\hline & & $\mathbf{F}$ & $\%$ & $\mathbf{F}$ & $\%$ & $\mathbf{F}$ & $\%$ & $\mathbf{F}$ & $\%$ & f & $\%$ & \\
\hline 1 & $\begin{array}{l}\text { Support was given from school and } \\
\text { parents to encourage students learning } \\
\text { through MT }\end{array}$ & 45 & 11.4 & 49 & 12.4 & 22 & 5.6 & 124 & 31.4 & 155 & 39.2 & .167 \\
\hline 2 & $\begin{array}{l}\text { Ethnic backgrounds of students is } \\
\text { fitting with language preferences of } \\
\text { students as medium of instruction }\end{array}$ & 85 & 21.5 & 111 & 28.1 & 18 & 4.6 & 96 & 24.3 & 85 & 21.5 & 3.025 \\
\hline 3 & $\begin{array}{l}\text { The social backgrounds of students go } \\
\text { along with medium of instruction }\end{array}$ & 44 & 11.1 & 48 & 12.1 & 21 & 5.3 & 123 & 31.1 & 159 & 40.3 & .964 \\
\hline 4 & $\begin{array}{l}\text { Learning upper primary education } \\
\text { through Afan Oromo increases } \\
\text { confidence of students }\end{array}$ & 46 & 11.6 & 37 & 9.4 & 20 & 5.1 & 136 & 34.4 & 156 & 39.5 & .561 \\
\hline
\end{tabular}

Table value of $\mathrm{t}$-test $=1.98$ at 0.05 significance level.

In item 1 Table 2, $16(35.6 \%)$ of the teacher respondents respectively responded strongly disagree $9(20.0 \%)$ and disagree $7(15.6 \%)$. While of the $21(46.6 \%)$ teacher respondents respectively responded agree 11 (24.4) and 10 $(22.2 \%)$ of the teacher respondents strongly agree with the sufficient support was given from school and parents to encourage students learning through MT. Only 8 (17.8\%) of teacher respondents expressed their feelings as undecided.

Correspondingly, students were also asked to indicate their views as to support were given from school and parents to encourage students learning. In line with this, 94 (23.8) of the student respondents respectively responded strongly disagree 45 (11.4\%) and disagree 49 (12.4\%). While, 279 (76.0\%) of the student respondents respectively responded agree 124
(31.4\%) and $155(39.2 \%)$ of the respondents strongly agree with the statement support was given from school and parents to encourage students learning using mother tongue. Only $22(5.6 \%)$ of students respondents expressed their feelings as undecided. Thus it can be concluded that the respondents' responses suggested that support given to the schools by various bodies was medium.

The calculated t-value (.167) at 0.05 significant level is less than the table value 1.98 . So, there is no significant difference between the opinions of the two groups of respondents. Consequently, one can conclude that the students' and teachers' agreed on the fact that support given to the schools by various bodies was remarkably medium. In supporting with this fact [11] regarding educational support 
given to enable students to succeed in their academic advancement, various concerned bodies have their own share.

In item 2 Table $2,7(15.6 \%)$ of the teacher respondents respectively responded strongly disagree $3(6.7 \%)$ and disagree $4(8.9 \%)$. While of the $36(80.0 \%)$ teacher respondents respectively responded agree 20 (44.4) and 16 $(35.6 \%)$ of the teacher respondents strongly agree with Ethnic backgrounds of students is fitting with language preferences of students as medium of instruction. Only 2 $(4.4 \%)$ of teacher respondents expressed their feelings as undecided.

Students were also asked to indicate their Ethnic backgrounds of students are fitting with language preferences of students as medium of instruction. In line with this, 196 (49.6) of the student respondents respectively responded strongly disagree $85(21.5 \%)$ and disagree 111 (28.1\%). While, $181(45.8 \%)$ of the student respondents respectively responded agree $96(24.3 \%)$ and $85(21.5 \%)$ of the respondents strongly agree with the statement that indicate ethnic backgrounds of students is fitting with language preferences of students as medium of instruction.

Thus, it can be concluded that the data obtained from students' responses to the questions show that the majority of the students preferred the use of Afan Oromo in education the primary schools. English was also the second preferred language as a medium of instruction in schools. The calculated t-value (3.025) at 0.05 significant level is greater than the table value 1.98 . So, there is significant difference between the opinions of the two groups of respondents. This may be from the fact that ethnic backgrounds of students is fitting with language preferences of students as medium of instruction. This was due to the level of understanding between teachers and students.

The interviews conducted school directors revealed that the majority of the communities needed education through their language, but they wanted English as a medium of instruction in the primary school thinking English issued as a medium of instruction in secondary schools.

In item 3 Table 2, $9(20.0 \%)$ of the teacher respondents respectively responded strongly disagree $2(4.4 \%)$ and disagree $7(15.6 \%)$. While of the $32(71.1 \%)$ teacher respondents respectively responded agree 15 (33.3\%) and 17 $(37.8 \%)$ of the teacher respondents strongly agree with the social backgrounds of students go along with medium of instruction, only $4(8.9 \%)$ of teacher respondents expressed their feelings as undecided.

Similarly, students were also asked to indicate their views as to support were given from school and parents to encourage students learning. In line with this, 83 (21.0\%) of the student respondents respectively responded strongly disagree $46(11.6 \%)$ and disagree 49 (12.4\%). While, 292 $(73.9 \%)$ of the student respondents respectively responded agree $136(34.4 \%)$ and $156(39.5 \%)$ of the respondents strongly agree on the question that deals with social backgrounds of students go along with medium of instruction.
But, $20(5.1 \%)$ of students respondents expressed their feelings as undecided. Thus, it can be concluded that the respondent's responded suggested that the social backgrounds of students go along with medium of instruction.

In supporting this idea language ideologies are highly contextualized and dependent upon many factors. They are formed through historical and socio-cultural circumstances and influenced by-the experience of a particular social position [12].

In item 4 Table 2, $12(26.7 \%)$ of the teacher respondents respectively responded strongly disagree $3(6.7 \%)$ and disagree $9(20 \%)$. While of the $25 \quad(55.6 \%)$ teacher respondents respectively responded agree 13 (28.9) and 12 $(26.7 \%)$ of the teacher respondents strongly agree with learning upper primary education through Afan Oromo increases confidence of students. Only $8(17.8 \%)$ of teacher respondents expressed their feelings as undecided. Students were also asked to indicate their confidence of in learning with Afan Oromo language. In line with this, 83 (21.0) of the student respondents respectively responded strongly disagree $46(11.6 \%)$ and disagree $37(9.4 \%)$. While, $292(73.9 \%)$ of the student respondents respectively responded agree 136 $(34.4 \%)$ and $156(39.5 \%)$ of the respondents strongly agree with the convenience of learning upper primary education through Afan Oromo increases confidence of students.

Overall, the majority of the students explicated that they had good confidence towards learning primary education through Afan Oromo. However, a few of them remarked that they had low confidence. Thus one can conclude that, learning upper primary education through Afan Oromo increases confidence of students. The calculated t-value (.561) at 0.05 significant level is less than the table value 1.98 . So, there is no significant difference between the opinions of the two groups of respondents. The implication is both groups of respondents have the perception that learning upper primary education through Afan Oromo increases confidence of students.

The interview held with school directors showed almost the same result. For instance, one of the school director (D1) expressed his views as: teaching through Afan Oromo was profoundly important for students, teachers and communities as it is related to their identity and social psychology. In supporting the above idea [13] asserted that the confidence of the students increased if they are familiar with medium of instruction before, because it helps to understand the content deeply.

\subsection{Challenges of Using Afan Oromo as Mother Tongue}

Attitudinal challenges of using Afan Oromo as mother tongue.

The existence of negative attitudes towards the use of Afan Oromo in education identified some factors as presented and analyzed in the following table: 
Table 3. Attitudinal challenges of using Afan Oromo as medium of instruction.

\begin{tabular}{|c|c|c|c|c|c|c|c|c|c|c|c|}
\hline \multirow{3}{*}{ S. № } & \multirow{3}{*}{ Items } & \multicolumn{10}{|c|}{ Respondent Teachers } \\
\hline & & \multicolumn{2}{|c|}{ Strongly Disagree } & \multicolumn{2}{|c|}{ Disagree } & \multicolumn{2}{|c|}{ Undecided } & \multicolumn{2}{|c|}{ Agree } & \multicolumn{2}{|c|}{ Strongly agree } \\
\hline & & $\mathbf{F}$ & $\%$ & $\mathbf{F}$ & $\%$ & $\mathbf{F}$ & $\%$ & $\mathbf{F}$ & $\%$ & $\mathbf{F}$ & $\%$ \\
\hline 1 & Limits students' understanding and knowledge. & 13 & 28.9 & 7 & 15.6 & 2 & 4.4 & 13 & 28.9 & 10 & 22.2 \\
\hline 2 & $\begin{array}{l}\text { Hinders students' academic performance at higher } \\
\text { institution. }\end{array}$ & 8 & 17.8 & 7 & 15.6 & 2 & 4.4 & 14 & 31.1 & 14 & 31.1 \\
\hline 3 & $\begin{array}{l}\text { The students perceive that learning through Afan } \\
\text { Oromo make them weak in English subject }\end{array}$ & 9 & 20.0 & 8 & 17.8 & 4 & 8.9 & 17 & 37.8 & 7 & 15.6 \\
\hline 4 & $\begin{array}{l}\text { Negative perception of parents and local } \\
\text { communities towards learning using Afan Oromo }\end{array}$ & 10 & 22.2 & 9 & 20.0 & 4 & 8.9 & 11 & 24.4 & 11 & 24.4 \\
\hline
\end{tabular}

Table 3. Continue.

\begin{tabular}{|c|c|c|c|c|c|c|c|c|c|c|c|c|}
\hline \multirow{3}{*}{ S. № } & \multirow{3}{*}{ Items } & \multicolumn{11}{|c|}{ Respondent students } \\
\hline & & \multicolumn{2}{|c|}{ Strongly Disagree } & \multicolumn{2}{|c|}{ Disagree } & \multicolumn{2}{|c|}{ Undecided } & \multicolumn{2}{|c|}{ Agree } & \multicolumn{2}{|c|}{ Strongly agree } & \multirow{2}{*}{ t- value } \\
\hline & & $\mathbf{F}$ & $\%$ & $\mathbf{F}$ & $\%$ & $\mathbf{F}$ & $\%$ & $\mathbf{F}$ & $\%$ & $\mathbf{F}$ & $\%$ & \\
\hline 1 & $\begin{array}{l}\text { Limits students' understanding and } \\
\text { knowledge. }\end{array}$ & 59 & 14.9 & 75 & 19.0 & 25 & 6.3 & 121 & 30.6 & 115 & 29.1 & -.373 \\
\hline 2 & $\begin{array}{l}\text { Hinders students' academic performance } \\
\text { at higher institution. }\end{array}$ & 73 & 18.5 & 69 & 17.5 & 15 & 3.8 & 120 & 30.4 & 118 & 29.9 & 1.230 \\
\hline 3 & $\begin{array}{l}\text { The students perceive that learning } \\
\text { through Afan Oromo make them weak } \\
\text { in English subject }\end{array}$ & 75 & 19.0 & 90 & 22.8 & 23 & 5.8 & 108 & 27.3 & 99 & 25.0 & 1.334 \\
\hline 4 & $\begin{array}{l}\text { Negative perception of parents and local } \\
\text { communities towards learning using } \\
\text { Afan Oromo }\end{array}$ & 83 & 21.0 & 95 & 24.1 & 19 & 4.8 & 101 & 25.6 & 97 & 24.6 & 1.367 \\
\hline
\end{tabular}

In item 1 of Table 3 which deals with fear of students in acquisition of advance knowledge by using Afan Oromo in upper primary schools, $20(44.4 \%)$ of the teacher respondents respectively responded strongly disagree $13(28.9 \%)$ and disagree 7 (15.6\%). While $23(51.1 \%)$ of the teacher respondents respectively responded agree $13(28.9 \%)$ and 10 $(22.2 \%)$ of the teacher respondents strongly agree with the negative attitude that states using MT limits students' understanding and knowledge. Only $2(4.4 \%)$ of teacher respondents expressed their feelings as undecided.

Similarly, students were also asked to indicate their views as if there are problems of using Afan Oromo as a medium of instruction. In line with this, 134 (33.9) of the student respondents respectively responded strongly disagree 59 (14.9\%) and disagree 75 (19\%). While, 236 (59.7\%) of the student respondents respectively responded agree $121(30.6 \%)$ and $115(29.1 \%)$ of the respondents strongly agree with the statement that using MT Limits students' understanding and knowledge. None of the student respondents expressed their feelings as undecided. Thus one can conclude that there is fear of using MT Limits students' understanding and knowledge. The calculated t-value $(-.373)$ at 0.05 significant levels with 125 degree of freedom is less than the table value 1.98. So, there is no significant difference between the opinions of the two groups of respondents. The implication is both groups of respondents have the perception that using MT Limits student' understanding and knowledge indicating the existence of consensus.

Concerning the issue shown in item 2 Table 3, 15 (33.4\%) of the teacher respondents respectively responded strongly disagree $8(17.8 \%)$ and disagree $7(15.6 \%)$ with the statement that using MT hinders students' academic performance at higher institution. Whereas $28(62.2 \%)$ of the teacher respondents respectively responded agree 14 (31.1\%) and 14 $(31.1 \%)$ of the teacher respondents strongly agree. Only 2 $(4.4 \%)$ of teacher respondents expressed their feelings as undecided. Similarly, students were also asked to indicate their views of using MT in upper primary school hinder students' academic performance at higher institution. In line with this, 238 (62.6) of the student respondents respectively responded strongly agree 118 (29.9\%) and agree 120 (30.4\%) While, $142(36.6 \%)$ of the student respondents respectively responded disagree $69(17.1 \%)$ and $73(18.5 \%)$ of the respondents strongly disagree with the statement that using MT in upper primary school hinder students' academic performance at higher institution. Only $15(3.8 \%)$ of students respondents expressed their feelings as undecided. Thus it can be conclude that teachers, parents, students and local communities assumed that education through mother tongue might hinder students future learning since mother tongue might have no continuation in future academy in secondary education and beyond. The calculated t-value (1.230) at 0.05 significant levels with 125 degree of freedom is less than the table value 1.98. So, there is no significant difference between the opinions of the two groups of respondents. The implication is both groups of respondents have the perception that using MT in upper primary school hinders students' academic performance at higher institution.

In item 3 Table 3, $17(37.8 \%)$ of the teacher respondents respectively responded strongly disagree 9 (20.0\%) and disagree $8(17.8 \%)$. While $24(53.4 \%)$ of the teacher respondents respectively responded agree $17(37.8 \%)$ and 7 $(15.6 \%)$ of the teacher respondents strongly agree with the statement that students perceive learning through Afan Oromo make them weak in English subject. Similarly, students were also asked to indicate their views as the impact 
of Afan Oromo in student's future. In line with this, 165 (41.8) of the student respondents respectively responded strongly disagree $75(19 \%)$ and disagree 90 (22.8\%). While, 207 $(52.3 \%)$ of the student respondents respectively responded agree $108(27.3 \%)$ and $99(25.0 \%)$ of the respondents strongly agree with the statement that perception of the students that learning through Afan Oromo make them weak in English subject. Thus it can be conclude that students perceive learning through Afan Oromo make them weak in English subject. The calculated t-value (1.334) at 0.05 significant level is less than the table value 1.98 . So, there is no significant difference between the opinions of the two groups of respondents. The implication is both groups of respondents have perception that students perceive learning through Afan Oromo make them weak in English subject indicating the existence of consensus.

The interviewee believed that the problem was not the use of Afan Oromo in education, but the methods used to teach Afan Oromo had methodological shortcomings. According to the interviewee, the ways Afan Oromo was taught as a subject had negative impacts on the methods used to teach English as a subject in primary schools.

With regard to parents' attitude towards using Afan Oromo as a medium of instruction; item 4 Table 3, 22 (48.8\%) of the teacher respondents respectively responded strongly disagree $11(24.4 \%)$ and disagree $11(24.4 \%)$. While 19 (42.2\%) of the teacher respondents respectively responded agree $9(20.0 \%)$ and $10(22.2 \%)$ of the teacher respondents strongly agree. Only $4(8.9 \%)$ of teacher respondents expressed their feelings as undecided. This shows the teacher respondents disagreed with the views negative perception of parents and local communities towards learning using Afan Oromo.

Students were also asked to indicate the views of parents and local communities towards using Afan Oromo as a medium of instruction. In line with this, 198 (50.2\%) of the student respondents respectively responded strongly agree 97 $(24.6 \%)$ and agree $101(25.6 \%)$, so as to indicate there is negative perception of parents in using Afan Oromo as a medium of instruction. While, $178(45.1 \%)$ of the student respondents respectively responded disagree $95(24.1 \%)$ and $83(21 \%)$ of the respondents strongly disagree $19(4.8 \%)$ the student respondents expressed their feelings as undecided. Thus, it can be conclude that both respondents disagreed with the views negative perception of parents and local communities towards learning using Afan Oromo. The calculated t-value (1.367) at 0.05 significant level is less than the table value 1.98 . So, there is no significant difference between the opinions of the two groups of respondents. The implication this is both groups of respondents disagreed to the fact that negative perception of parents and local communities towards learning using Afan Oromo indicating existence of consensus.

As stated by the interviewee, people aspired for the use of English as a medium of instruction in primary school at the expense of Afan Oromo. He had the view that people's aspiration for English and their preference for this language to become a medium of instruction in primary schools affected the development of Afan Oromo in education. In this regard, [14] also noticed, "It is generally assumed that English is inherently superior and better suited in education."

In this view, the use of mother tongue in education was discouraged in most of the African countries that were under the impact of colonial power and ideology. According to the interviewee, there are peoples that have fear of using Afan Oromo as a medium of instruction in upper primary schools might have negative impact on the future students' achievement some people think that students' proficiency in English could be weaker if they learned primary education through Afan Oromo (mother tongue). As a result, as stated by interviewee, students might fail in national examinations given at grades 10 and 12. With supporting this idea [15] showed her doubt about the success of students on grade 8 and grade 10 national exam and the achievement of students in the higher education.

\section{Summary of the Findings, Conclusions and Recommendations}

\subsection{Summary of the Findings}

Based on the analysis of the data, the following major findings were obtained:

1. With regard to the availability of teacher in using Afan Oromo as medium of instruction, majority of respondent teachers $(75.5 \%)$ of reported that Afan Oromo was a medium of instruction that they were trained in. In addition, with regard to students' proficiency in Afan Oromo, majority (69.4\%) of the teachers stated that students' overall proficiency was relatively very good in all language skills such as reading ability, speaking ability, writing ability, and listening skill;

2. Majority of the students $(55.6 \%)$ and the majority of the interviewee indicated that their teachers encourage dialogue and debate by their mother tongue. The overall evidence reveals that the majority of the teachers and school directors seemed to advise and encourage students to be better learners in the academy. Moreover, majority $(60 \%$ of the respondent teachers) indicate that with teachers in using Afan Oromo as a medium of instruction in using authentic examples from students' cultures and experiences.

3. The majority of the respondent students (73.9\%) indicate the convenience of learning upper primary education through Afan Oromo increases confidence of students. The majority of the respondent teachers $(53.3 \%)$ and $33.3 \%$ respondent students indicate using MT have advantage in reducing dropout rates and repetition rate.

4. 57.9\% of the student respondents fear for that they might not successful in grade 10 national examination because of using MT in upper primary school. There are many students that have fear of learning through MT for its influence in their futures education. 


\subsection{Conclusions}

Based on the findings of the study the following conclusions are made.

1. The study found that there are limited practices that show the presence of practice of using Afan Oromo as a medium of instruction education. However, these practices were challenged by many problems such as material, absence of adequate support and attitudinal problems. Hence, the major practices, challenges and opportunities that were identified in relation to using Afan Oromo as a medium of instruction were presented as follows:

2. In supporting the practice of using Afan Oromo as a medium of instruction there are teachers' activities such as using authentic examples from students' cultures and experiences; and tutorial sections given for students on the difficulty of Qubee based writing style.

3. There is shortage of reference books that was written by Afan Oromo that has great impact in using Afan Oromo as medium of instruction. Besides, upper primary school teachers should not get training on the method of teaching using mother tongue as a medium of instruction, thus, most teachers did not use efficient and innovative methods of teaching and this affect the quality of education negatively.

\subsection{Recommendations}

Based on the study, the key findings and conclusions drawn above, recommendations were made below.

1. The first implication for practical issues on the ground and the fact of a linguistic situation are of paramount significance to be considered. Therefore, the practicality of the mother tongue in education on the grounds should be identified prior to its implementation. Before implementing mother-tongue education, quality educational materials in mother tongue should be prepared.

2. The second implication is the quality of teachers working in mother-tongue education can affect children's academic performances and their future academic achievements. Specifically, if teachers are inefficient and use innovative and active methods of teaching, the quality of mother-tongue education can be hampered. Thus, on-the-job training should be arranged for teachers and others to enhance the using Afan Oromo as a medium of instruction.

3. The concerned bodies should work together to enhance school improvement activities and teachers' professional development; On-job training should be given to teachers on the methods of teaching mother tongue to up-grade their teaching skills, to enhance their confidence in their teaching and to build their creativities in teaching and assessing students' learning; Awareness raising activities about mother-tongue use in education should be given to teachers, students, parents and local communities; the strategies used to teach Afan
Oromo should be used as a basis to teach English or other languages.

\section{References}

[1] Teshome, N. (2003). The impact of with the mother on academic achievement: A case study of grade 8 students in Ethiopia. Learning with mother tongue.

[2] Federal Negarit Gazeta (1995). The constitution of 1995 of The Federal Democratic Republic of Ethiopia. Addis Ababa, 21 August 1995, $1^{\text {st }}$ Year, No 1.

[3] FDRGE/TGE (1994). Education and Training Policy. Addis Ababa: St. George Printing Press.

[4] Jeylan Gobana (2014). Challenges of Mother-Tongue education in Primary Schools: The Case of Afan Oromo in the Eastern Hararge Zone, Oromia Reagional State, Ethiopia. (Doctoral Thesis). University of South Africa.

[5] Seyoum, H. (2009). Language policy and access to education. Reversing the quest of the centuries and passing toward the uncharted future. Kyoto: Nakanishi Printing Co., Ltd.

[6] Benson and Kosonen, K. (2010). 'Language in Education Policy and Practice in Southeast Asian in the Light of Findings from Ethiopia.' In Heugh, K and Skatnabb-Kangas, T, (Eds.) Multilingual Works from the Periphery to the Centre.

[7] UNESCO (2005). Education for all, The quality imperative, EFA Global Monitoring report 2005, Paris; 2000, The Dakar framework for Action: Education for All. Meeting our collective commitments, Dakar: World education Forum.

[8] Cohen, G. P. E (2007). "Mother tongue and other tongue in primary education: Can equity be achieved with the use of different languages? Addis Ababa, Ethiopia, 26-28 October 2005.

[9] Slovin (1960). How to use Slovin formula. http://WWW.Statisticshowto.com.html.

[10] Dash, N. K. (2005). Module: Selection of the research paradigm and methodology. Online Research Methods Resource for Teachers and Trainers. Retrieved from http://www.celt.mmu.ac.uk/researchmethods/Modules/Selecti on_of_methodology/index.php.

[11] Burton, Lisa Ann (2013). Mother Tongue-Based Multilingual Education in the Philippines: Studying Top-Down Policy Implementation from the Bottom Up, A Dissertation Submitted to the faculty of University of Minnesota, In Partial Fulfillment of the Requirements for the Degree of Doctor of Philosophy.

[12] Woolard, K., Schieffelin, B., \& Kroskrity, P. (eds.) (1998). Language ideologies: Practice and theory. Oxford, England: Oxford University Press.

[13] Alexander R. (2005). Culture and Pedagogy: International Comparisons in Primary Education. Oxford: Blackwell Publishers.

[14] Mutasa, D. E. (2003). The language policy of South Africa: what do people say? ( $\mathrm{PhD}$ dissertation: Electronic Theses and Dissertations). 
Bezabih Wondimu, and Tesfaye Guta: Practices, Challenges and Opportunities of Using Afan Oromo as a Medium of Instruction in Upper Primary Schools of Berbere Woreda, Bale Zone, Oromia, Ethiopia

[15] Tihtina Zenebe Gebre (2013). Effects of Mother-Tongue Education on Schooling and Adult Outcomes: Evidence from Ethiopia. Economics Department, University of Notre Dame. 